\title{
Exploring the Relationship between Quality of Sleep and Learning Satisfactions on the Nursing College Students
}

\author{
Hsiu-Chin Hsu1, Ting-En Chen2, Chia-Hsuan Lee ${ }^{3}$, Whei-Mei Jean Shih4, Mei-Hsiang Lin4* \\ ${ }^{1}$ Department of Nursing, Chang-Gung University of Science and Technology, Taoyuan, Chinese Taipei \\ ${ }^{2}$ Ginzhi Consulting Co., Ltd., Taoyuan, Chinese Taipei \\ ${ }^{3}$ Department of Nursing, Chang Gung University, Taoyuan, Chinese Taipei \\ ${ }^{4}$ Graduate Institute of Health Care, Chang-Gung University of Science and Technology, Taoyuan, Chinese Taipei \\ Email: "
}

Received 14 May 2014; revised 25 June 2014; accepted 13 July 2014

Copyright (C) 2014 by authors and Scientific Research Publishing Inc.

This work is licensed under the Creative Commons Attribution International License (CC BY).

http://creativecommons.org/licenses/by/4.0/

(c) (i) Open Access

\begin{abstract}
Background and Aim: Quality of sleep is essential element for learning and memory. Students' learning performance may be affected by sleep. The purpose of this study was to explore the relationship between quality of sleep and learning satisfaction on nursing college students. Design and Participants: A cross-sectional with correlation study design was employed. 200 students were recruited from the nursing college. Pittsburgh Sleep Quality Index and Learning Satisfaction Scale were used for data collection. SPSS for window 17.0 was used for data analysis. Results: Findings showed: 1) $53 \%$ of participants rated their sleep quality as poor; 2 ) the global learning satisfaction of participants varied between highly satisfaction and satisfaction; 3) the global learning satisfaction was significantly negative related to "subjective sleep quality", "use the sleep pill", and "daytime dysfunction" ( $<$ 0.05), finally, students who were interested in nursing can be explained $10.2 \%$ of the total amount of variances in learning satisfaction. Conclusions: The findings can provide information regarding nursing students' sleep status and learning satisfaction to school teacher. The information would be helpful as evidences when laying out nursing curriculum to strengthen students' sleep hygiene and learning of affective domain in the future.
\end{abstract}

\section{Keywords}

Sleep Quality, Learning Satisfaction, College Students, Affective Domain

\footnotetext{
${ }^{*}$ Corresponding author.
}

How to cite this paper: Hsu, H.-C., Chen, T.-E., Lee, C.-H., Shih, W.-M.J. and Lin, M.-H. (2014) Exploring the Relationship between Quality of Sleep and Learning Satisfactions on the Nursing College Students. Health, 6, 1738-1748. 


\section{Introduction}

Learning satisfaction is an indicator for evaluating student learning effectiveness and the teaching quality of educators [1]. Bloom [2] suggested that based on teaching objectives, learning effectiveness could be categorized into cognitive, psychomotor, and affective domains. To comprehensively capture the learning effectiveness of college education, evaluation of learning effectiveness among college students should cover "cognitive”, "affective", and "psychomotor" domains. The cognitive domain of teaching objectives addresses the acquisition of concepts and knowledge and the cultivation of thinking and innovative abilities. The psychomotor domain focuses on the development of movements and the proficiency of skills. Regarding the affective domain of teaching objectives, the nurturing of moral character and establishment of values are emphasized [3].

A study indicated that affective education developed morals, discipline, affection, and attitudes, etc., and that the affective performance of college students would affect their professional spirit and attitude in their future work [4]. Nursing education covers the acquisition of professional knowledge, the training of professional skills, and the development of a professional attitude [5]. Standing from this perspective, Wang and Lin [1] defined learning satisfaction in nursing students as the subjective perception or attitude toward the level of achievement in the cognitive, psychomotor, and affective domains. Understanding student learning satisfaction is important to the professional training of nursing students. Nursing students' satisfaction with learning clinical experiences suggests their perceptions and attitudes toward the learning activities, and these perceptions and attitudes are shaped as students enjoy the learning activities or fulfill their wishes or needs during the learning process [6]. Studies have shown that factors affecting learning satisfaction included grades, motivation, academic performance, and interest [1] [6].

However, it is noteworthy that given the freedom of study, the various activities in colleges, and universal internet availability, college students may be staying up late using the Internet, leading to increasing problems of sleep irregularity such as sleeping late [7]. Vail-Smith et al. [8] studied sleep quality and health risk factors in 859 college students in the US. The results suggested that $76.6 \%$ of students experienced sleep problems, and $11.8 \%$ of students had poor sleep quality. Tsai and Li [9] studied sleeping pattern in 237 college students, and found that sleep problems were common in general college students. However, given the changes in academic pressure and lifestyles, students have to sacrifice their sleep for study, and continuous sleep deficiency could not only lead to reduced brain function, but could affect student mental health and their day-to-day lives [10]. These findings highlight the sleep-related issues among college students. Sleep is a basic physiological need, and it is fundamental for maintaining good health. In addition, sleep duration is one of the predictors of health and mortality. Insufficient sleep causes damage to the hippocampus, which not only affects cognitive skills such as memory, learning, reasoning, and calculating, but influences language and judgment abilities [11].

Memory and learning abilities may be affected by sleep. Many studies regarding sleep-related issues among students have led to different results. Forquer et al. [12] conducted an investigation in 313 college students and found that students had poor subjective sleep quality. Long-term sleep disorder not only affects physical and mental conditions, but also indirectly influences learning efficiency. Sleep disturbances cause irregular sleep patterns, and continuous delays and interruptions in sleep duration could lead to disorders such as sleep deprivation, delayed sleep phase syndrome (DSPS), and daytime sleepiness [7]. Furthermore, long-term sleep disorders increase the risk of affective disorders such as depression, and play a significant role in deteriorating health. Though sleep disorders do not bring immediate influences on physical or mental health, it could be related to life-threatening accidents, or affect quality of life and daily performance [13]. As a result, the influence of sleep problems merits attention.

Fewer studies investigated the relationship between learning satisfaction and sleep quality. A great amount of research regarding sleep and learning effectiveness exists. Meijer et al. [14] studied sleep behavior among junior high school students, and revealed that subjective sleep quality was related to academic performance. When in school, those with better subjective sleep quality were more likely to learn from teachers, and showed stronger motivation for academic achievement. Sleep quality could pose an influence on academic performance via the volume of sleep, subjective sleep quality, and time of awakening during weekdays and in weekends, where subjective sleep quality is the major predictor [15]. A study found a negative relationship between academic performance and sleep quality and sleeping patterns among teenagers; individuals with poorer sleep quality, shorter sleep duration, and more irregular time of wakefulness demonstrated worse academic performance [16]. Many studies have shown that among teenagers, sleep deprivation had an adverse effect on academic performance [16] 
[17]. A study found that those who had better academic performance kept a more regular time of sleep and wakefulness during weekdays, had longer total sleep duration, and were less likely to feel sleepy during the daytime [18].

Lazaratou et al. [19] studied sleep quality among 713 teenagers, and found that students with sleep disorders had lower academic performance. Sleep duration of less than 8 hours and frequent nightmares while asleep could increase the chances of future deviant behavior [13]. A few previous studies investigated the relationship between learning satisfaction and quality of sleep. It is crucial to investigate both quality of sleep and learning satisfaction for nursing students. Therefore, the purpose of this study was to explore the relationship between learning satisfaction and sleep quality among nursing college students.

\section{Measures}

\subsection{Study Design and Population}

This cross-sectional study adopted students of an Institute of Technology in 2010 as the study population. The class as a unit, stratified cluster random sampling based on the number of classes was used to recruit fourth and fifth year students. A structured questionnaire was used to collect data on the factors affecting sleep quality and learning satisfaction in nursing students. Power analysis was used to calculate the appropriate sample size. This study referred to Polit and Beck's [20] study, which suggested adopting an effect size of 0.2, power of 0.8, and $\alpha$ as 0.05 for nursing-related studies. The calculated sample size was 197. Questionnaires were sent to samples be self-administered. A total of 207 students responded, yielding a response rate $96 \%$.

\subsection{Measures}

Demographic Data Questionnaire: The demographic questionnaire contained information on the year of study, participation in extracurricular activities, holding of part-time jobs, motivation to study nursing, semester scores, and interest in nursing of the students.

Chinese version of the Pittsburgh Sleep Quality Index (C-PSQI): We used the translated (Chinese) version of the Pittsburgh Sleep Quality Index of Chiang [21], originally developed by Buysse, Reynolds III, Monk et al. [22]. This is a self-rated questionnaire which assesses sleep quality and disturbances over a 1-month time interval. Nineteen individual items generated seven "component" scores: subjective sleep quality, sleep latency, sleep duration, habitual sleep efficient, sleep disturbances, use of sleeping medication, and daytime dysfunction. The seven components were scored from 0 to 3 points, with each component weighted equally. A score of " 0 " indicated no difficulty, while a score of " 3 " represented severe difficulty. The possible total scores of the seven components ranged from 0 to 21. A higher score signified worse sleep quality. "Poor sleep" was defined as a PSQI score of greater than 5 [22]. The Cronbach's $\alpha$ value for this study was 0.83 .

Learning Satisfaction Scale: The 22-item scale, which was developed by Wang and Lin [1] study, which focused on the relationship between perceptions toward clinical nursing instructors' caring behavior and learning satisfaction among nursing students. The scale of learning satisfaction contains affective, cognitive, and psychomotor domains, and a 4-point Likert scale was applied. A score of 4 points represents "highly satisfied", a score of 3 points represents "satisfied", a score of 2 points suggests "dissatisfied", and a score of 1 point indicates "highly dissatisfied". The Cronbach's $\alpha$ value was 0.88 , implying the internal consistency of the original scale, and the Cronbach's $\alpha$ value for this study was 0.96 .

\subsection{Human Subject Protection and Data Collection Procedure}

This study was approved by the Institutional Review Board of the medical center (IRB approval number: 1002571D) and the administrative departments of the school before the authors began to recruit participants. To protect the rights of the study participants, the authors first explained the study purpose and the data collection procedure to participants in the class meeting. After signing a consent form, participants would receive the study questionnaire. If they felt any discomfort or inappropriateness during the study, participants could freely withdraw from the study at any time. The questionnaires were anonymous, and the collected data were coded for further statistical analysis. To ensure participants' privacy, this study would not disclose the results of any participants. 


\subsection{Statistical Analysis}

SPSS for Windows (Version 17.0; SPSS, Inc., Chicago, IL, USA) was used for data analysis. To describe the distribution of demographic data, sleep quality, and learning satisfaction, we used descriptive statistics expressed in terms of frequency, percentage, mean, and standard deviation. We tested the differences learning satisfaction and demographic data using a t test or a one-way ANOVA and the Scheffe's method. We tested correlation among sleep quality, and learning satisfaction using Pearson's product-moment correlation. Stepwise multiple regression was used to identify predictors of learning satisfaction, and significance level $p$ value was set at 0.05 .

\section{Results}

\subsection{Description of the Participants Learning Satisfaction, and Sleep Quality}

Most of the study participants studying at the 5-year junior college were in their fifth year of study (52.5\%), and a large proportion of the participants did not participate in any extracurricular activities $(\mathrm{N}=133,66.5 \%)$. Most of the students did not have a part-time job (83\%), and half of the students studied nursing because their parents suggested them to do so. A total of 50\% of students reported "neutral" interest in nursing (Table 1). Regarding learning satisfaction, the mean score of overall learning satisfaction among participants was $3.05 \pm 0.37$ points, suggesting a satisfaction level between "highly satisfied" and "satisfied". As shown in Table 2, participants demonstrated the highest learning satisfaction toward the cognitive domain, followed by the psychomotor domain, and finally the affective domain. With respect to sleep quality, the mean total score of C-PSQI among the

\begin{tabular}{|c|c|c|}
\hline Variables & $\mathrm{n}$ & $\%$ \\
\hline \multicolumn{3}{|l|}{ Year of study } \\
\hline 4 & 95 & 47.5 \\
\hline 5 & 105 & 52.5 \\
\hline \multicolumn{3}{|l|}{ Participation in extracurricular activities } \\
\hline Yes & 67 & 33.5 \\
\hline No & 133 & 66.5 \\
\hline \multicolumn{3}{|l|}{ Holding of part-time jobs } \\
\hline Yes & 34 & 17 \\
\hline No & 166 & 83 \\
\hline \multicolumn{3}{|l|}{ Motivation to study nursing } \\
\hline Personal interest & 38 & 19.0 \\
\hline Influence from brothers/sisters & 10 & 5.0 \\
\hline Influence from classmates & 9 & 4.5 \\
\hline Parental suggestion & 100 & 50.0 \\
\hline Teacher suggestion & 5 & 2.5 \\
\hline School allocation based on the test scores & 17 & 8.5 \\
\hline A nursing background facilitates job hunting & 21 & 10.5 \\
\hline \multicolumn{3}{|l|}{ Semester grade } \\
\hline $60-69$ points & 12 & 6.0 \\
\hline $70-79$ point & 76 & 38.0 \\
\hline Above 80 points & 112 & 56.0 \\
\hline \multicolumn{3}{|l|}{ Interest in nursing } \\
\hline Highly interested & 11 & 5.5 \\
\hline Interested & 54 & 27.0 \\
\hline Neutral & 100 & 50.0 \\
\hline Not interested & 27 & 13.5 \\
\hline Not interested at all & 8 & 4.0 \\
\hline
\end{tabular}


Table 2. Sleep quality and learning satisfaction $(\mathrm{N}=200)$.

\begin{tabular}{|c|c|c|}
\hline Variable & n (\%) & $\mathrm{M} \pm \mathrm{SD}$ \\
\hline Learning Satisfaction & & $3.05 \pm 0.37$ \\
\hline Cognitive Domain & & $3.08 \pm 0.34$ \\
\hline Psychomotor Domain & & $3.04 \pm 0.38$ \\
\hline Affective Domain & & $2.97 \pm 0.53$ \\
\hline \multicolumn{3}{|l|}{ Sleep Quality } \\
\hline Subjective Sleep Quality & & $1.32 \pm 0.65$ \\
\hline Very Good & $14(7.0)$ & \\
\hline Fairly Good & $115(57.5)$ & \\
\hline Fairly Bad & $64(32.0)$ & \\
\hline Very Bad & $7(3.5)$ & \\
\hline Sleep Latency & & $0.56 \pm 0.72$ \\
\hline$\leq 15$ Minutes & $114(57.0)$ & \\
\hline 16 - 30 Minutes & $64(32.0)$ & \\
\hline 31 - 60 Minutes & $19(9.5)$ & \\
\hline$>60$ Minutes & $3(1.5)$ & \\
\hline Sleep Duration & & $1.09 \pm 1.06$ \\
\hline$>7$ Hours & $66(33.0)$ & \\
\hline$>6 \leq 7$ Hours & $90(45.0)$ & \\
\hline$\geq 5$ and $\leq 6$ Hours & $5(2.5)$ & \\
\hline$<5$ Hours & $39(19.5)$ & \\
\hline Habitual Sleep Efficient & & $0.33 \pm 0.72$ \\
\hline$\geq 85 \%$ & 159 (79.5) & \\
\hline $84 \%-75 \%$ & $24(12.0)$ & \\
\hline $74 \%-65 \%$ & $10(5.0)$ & \\
\hline$<65 \%$ & $7(3.5)$ & \\
\hline Sleep Disturbances & & $1.38 \pm 0.65$ \\
\hline Not during the Past Month & $6(3.0)$ & \\
\hline Less than Once a Week & $125(62.5)$ & \\
\hline Once or Twice a Week & $56(28.0)$ & \\
\hline Three or More Times a Week & $13(6.5)$ & \\
\hline Use of Sleeping Medication & & $0.07 \pm 0.40$ \\
\hline Not during the Past Month & $193(96.5)$ & \\
\hline Less than Once a Week & $3(1.5)$ & \\
\hline Once or Twice a Week & $1(0.5)$ & \\
\hline Three or More Times a Week & $3(1.5)$ & \\
\hline Daytime Dysfunction & & $1.05 \pm 0.93$ \\
\hline No Problem at All & $65(32.5)$ & \\
\hline Only a Very Slight Problem & 75 (37.5) & \\
\hline Somewhat of a Problem & $44(22.0)$ & \\
\hline A Very Big a Problem & $16(8.0)$ & \\
\hline C-PSQI Score & & $6.17 \pm 2.92$ \\
\hline$\leq 5$ & $94(47.0)$ & \\
\hline$>5$ & $106(53.0)$ & \\
\hline
\end{tabular}


study participants was $6.17 \pm 2.92$, representing that more than half of participants (53\%) had poor sleep quality. The authors further analyzed the scores of each sub-dimension of sleep quality and found that $35.5 \%$ of participants had poor subjective sleep quality. Regarding sleep latency, more than half of participants could fall asleep within $30 \mathrm{~min}$. The mean sleep duration among students was $6.19 \pm 0.98$ hours/day, and $19.5 \%$ of students slept fewer than 5 hours a day. Regarding habitual sleep efficiency, if $\geq 85 \%$ is taken as the standard for good sleep efficiency, $20.5 \%$ of students experienced poor sleep efficiency. About $34.5 \%$ of the study participants had experienced sleep disturbances more than once. With respect to use of sleep medication, only $4 \%$ of the study participants occasionally took sleeping pills, and $32.5 \%$ of participants reported that their daytime functions were not affected (Table 2).

\subsection{Differences between Demographic Characteristics and Learning Satisfaction}

"Year of study”, "participation in extracurricular activities”, "holding of a part-time job”, “motivation to study nursing", and "semester grades" were not found to be significantly related to overall learning satisfaction, while "interest in nursing" was significantly correlated. The authors further conducted a Scheffe's post hoc comparison and found that compared to students who answered "not interested at all" for "interest in nursing", those who answered "highly interested", "interested", "neutral”, or "not interested" had greater overall learning satisfaction. The study examined the relationships between demographic characteristics and the affective, cognitive, and psychomotor domains. The results show that interest in nursing was significantly associated with the affective and psychomotor domains. An additional Scheffe's post hoc comparison suggested that compared to students who answered "not interested at all" in terms of their interest in nursing, those who answered "highly interested", "interested", "neutral”, or "not interested" had greater learning satisfaction in the affective domain, and those who answered "interested" had greater learning satisfaction in the psychomotor domain (Table 3).

\subsection{Relationships between Learning Satisfaction and Sleep Quality}

The study results showed no significant relationship between overall learning satisfaction and C-PSQI score. However, a significantly negative relationship was observed between the affective domain of learning satisfaction and C-PSQI score $(\mathrm{r}=-0.141, \mathrm{p}<0.05)$, representing that a higher score in the affective domain of learning satisfaction was associated with a lower C-PSQI, which indicated better sleep quality. Regarding the analyses between overall learning satisfaction and different dimensions of sleep quality, overall learning satisfaction was found to be significantly and negatively associated with "subjective sleep quality", "use of sleep medication", and "daytime dysfunction". These findings indicated that lower scores in these three constructs were linked to greater overall learning satisfaction (Table 4).

This study further adopted learning satisfaction as the dependent variable, and incorporated "demographic characteristics" and "sleep quality" as independent variables, which were significantly correlated with overall learning satisfaction. The variable "interest in nursing" was first converted into a dummy variable, and then included in a stepwise multiple regression model for identifying its predictive power on learning satisfaction. The results show that learning satisfaction was significantly correlated with "interest in nursing" $(F=23.59, p<$ 0.01). That is, $10.2 \%$ of the variance in learning satisfaction could be explained by interest in nursing (Table 5).

\section{Discussion}

\subsection{Prevalence of Sleep Quality and Learning Satisfaction among College Nursing Students}

The mean C-PSQI score among the study participants was $6.17 \pm 2.92$ points, and $53 \%$ of participants had poor sleep quality. This study showed a higher prevalence of poor sleep quality than found by Tsai and Li [9]. The reason may be different department in which participants were general college students. However, the participants recruited in this study were in their fourth and fifth years of study at a junior college nursing school, the internship pressure may affect the sleep. Though the mean C-PSQI score indicated poor sleep quality, according to the scores of subjective sleep quality, approximately $65 \%(n=129)$ of students answered "good" and "very good" for their self-perceived sleep quality. This finding suggests that when paying attention to the individual feelings of subjective sleep is an important factor to solve sleep problems.

The results of this study showed that mean score of overall learning satisfaction level between "highly satis- 
Table 3. Comparisons of demographic and learning satisfaction among subjects $(\mathrm{N}=200)$.

\begin{tabular}{|c|c|c|c|c|}
\hline Variable & Affective domain & $\begin{array}{l}\text { Cognitive } \\
\text { domain }\end{array}$ & $\begin{array}{l}\text { Psychomotor } \\
\text { domain }\end{array}$ & $\begin{array}{l}\text { Overall learning } \\
\text { satisfaction }\end{array}$ \\
\hline \multicolumn{5}{|l|}{ Year of study } \\
\hline 4 & $2.93 \pm 0.58$ & $3.07 \pm 0.36$ & $3.00 \pm 0.40$ & $3.00 \pm 0.39$ \\
\hline \multirow[t]{2}{*}{5} & $3.01 \pm 0.49$ & $3.09 \pm 0.33$ & $3.08 \pm 0.37$ & $3.06 \pm 0.35$ \\
\hline & $\mathrm{t}=1.24$ & $\mathrm{t}=0.23$ & $\mathrm{t}=2.10$ & $\mathrm{t}=1.39$ \\
\hline \multicolumn{5}{|l|}{ Participation in extracurricular activities } \\
\hline Yes & $2.96 \pm 0.51$ & $3.08 \pm 0.37$ & $2.99 \pm 0.37$ & $3.01 \pm 0.37$ \\
\hline \multirow[t]{2}{*}{ No } & $2.98 \pm 0.54$ & $3.08 \pm 0.33$ & $3.06 \pm 0.39$ & $3.04 \pm 0.37$ \\
\hline & $\mathrm{t}=0.053$ & $\mathrm{t}=0.001$ & $\mathrm{t}=1.66$ & $\mathrm{t}=0.28$ \\
\hline \multicolumn{5}{|l|}{ Holding of part-time jobs } \\
\hline Yes & $2.97 \pm 0.64$ & $3.05 \pm 0.44$ & $3.00 \pm 0.43$ & $3.01 \pm 0.45$ \\
\hline \multirow[t]{2}{*}{ No } & $2.98 \pm 0.51$ & $3.08 \pm 0.32$ & $3.05 \pm 0.37$ & $3.04 \pm 0.35$ \\
\hline & $\mathrm{t}=0.001$ & $\mathrm{t}=0.21$ & $\mathrm{t}=0.39$ & $\mathrm{t}=0.16$ \\
\hline \multicolumn{5}{|l|}{ Motivation to study nursing } \\
\hline (1) Personal interest & $3.11 \pm 0.35$ & $3.11 \pm 0.33$ & $3.08 \pm 0.28$ & $3.10 \pm 0.25$ \\
\hline (2) Influences from brothers/sisters & $3.07 \pm 0.93$ & $3.15 \pm 0.37$ & $3.26 \pm 0.36$ & $3.16 \pm 0.52$ \\
\hline (3) Influences from classmates & $2.87 \pm 0.54$ & $3.04 \pm 0.46$ & $3.04 \pm 0.21$ & $2.98 \pm 0.37$ \\
\hline (4) Parental suggestion & $2.89 \pm 0.56$ & $3.05 \pm 0.35$ & $2.98 \pm 0.41$ & $2.97 \pm 0.39$ \\
\hline (5) Teacher suggestion & $2.97 \pm 0.35$ & $3.06 \pm 0.51$ & $3.08 \pm 0.50$ & $3.04 \pm 0.43$ \\
\hline (6) School allocation based on the test scores & $3.01 \pm 0.45$ & $3.06 \pm 0.28$ & $3.04 \pm 0.39$ & $3.04 \pm 0.34$ \\
\hline \multirow[t]{2}{*}{ (7) A nursing background facilitates job hunting } & $3.07 \pm 0.52$ & $3.16 \pm 0.31$ & $3.13 \pm 0.42$ & $3.12 \pm 0.37$ \\
\hline & $\mathrm{F}=1.03$ & $\mathrm{~F}=0.46$ & $\mathrm{~F}=1.14$ & $\mathrm{~F}=1.00$ \\
\hline \multicolumn{5}{|l|}{ Semester grade } \\
\hline (1) $60-69$ points & $2.84 \pm 0.53$ & $2.90 \pm 0.23$ & $3.00 \pm 0.26$ & $2.91 \pm 0.28$ \\
\hline (2) $70-79$ points & $2.90 \pm 0.59$ & $3.06 \pm 0.36$ & $2.97 \pm 0.41$ & $2.98 \pm 0.40$ \\
\hline \multirow[t]{2}{*}{ (3) above 80 points } & $3.04 \pm 0.49$ & $3.11 \pm 0.34$ & $3.09 \pm 0.37$ & $3.08 \pm 0.35$ \\
\hline & $\mathrm{F}=1.99$ & $F=2.26$ & $F=2.04$ & $\mathrm{~F}=2.40$ \\
\hline \multicolumn{5}{|l|}{ Interest in nursing } \\
\hline (1) Highly interested & $3.22 \pm 0.47$ & $3.21 \pm 0.49$ & $3.12 \pm 0.44$ & $3.18 \pm 0.43$ \\
\hline (2) Interested & $3.17 \pm 0.46$ & $3.15 \pm 0.35$ & $3.11 \pm 0.35$ & $3.15 \pm 0.33$ \\
\hline (3) Neutral & $2.97 \pm 0.47$ & $3.05 \pm 0.33$ & $3.05 \pm 0.40$ & $3.02 \pm 0.36$ \\
\hline (4) Not interested & $2.83 \pm 0.54$ & $3.04 \pm 0.29$ & $2.95 \pm 0.31$ & $2.94 \pm 0.31$ \\
\hline \multirow[t]{2}{*}{ (5) Not interested at all } & $1.87 \pm 0.42$ & $2.86 \pm 0.25$ & $2.62 \pm 0.32$ & $2.45 \pm 0.20$ \\
\hline & $\mathrm{F}=14.46^{* *}$ & $F=2.06$ & $\mathrm{~F}=3.41^{* *}$ & $\mathrm{~F}=7.85^{* *}$ \\
\hline Scheffee's & (1), (2), (3), (4) > (5) & & (2) $>$ (5) & (1), (2), (3), (4) $>$ (5) \\
\hline
\end{tabular}

${ }^{* *} \mathrm{p}<0.01$. 
Table 4. Relationships between learning satisfaction and sleep quality.

\begin{tabular}{|c|c|c|c|c|c|c|c|c|c|c|c|c|}
\hline Variable & 1 & 2 & 3 & 4 & 5 & 6 & 7 & 8 & 9 & 10 & 11 & 12 \\
\hline 1. Affective Domain & 1 & & & & & & & & & & & \\
\hline 2. Cognitive Domain & $0.651^{* *}$ & 1 & & & & & & & & & & \\
\hline 3. Psychomotor Domain & $0.671^{* *}$ & $0.681^{* *}$ & 1 & & & & & & & & & \\
\hline 4. Overall Learning Satisfaction & $0.910^{* *}$ & $0.855^{* *}$ & $0.876^{* *}$ & 1 & & & & & & & & \\
\hline 5. Subjective Sleep Quality & $-0.155^{*}$ & -0.135 & -0.114 & $-0.155^{*}$ & 1 & & & & & & & \\
\hline 6. Use of Sleep Medication & $-0.197^{* *}$ & -0.108 & $-0.165^{*}$ & $-0.184^{* *}$ & 0.047 & 1 & & & & & & \\
\hline 7. Sleep Latency & -0.033 & -0.048 & -0.077 & -0.057 & $0.352^{* *}$ & $0.171^{*}$ & 1 & & & & & \\
\hline 8. Sleep Duration & -0.112 & -0.063 & -0.077 & -0.099 & $0.306^{* *}$ & 0.125 & $0.185^{* *}$ & 1 & & & & \\
\hline 9. Habitual Sleep Efficient & 0.008 & -0.042 & 0.010 & -0.006 & $0.181^{*}$ & $0.143^{*}$ & $0.237^{* *}$ & $0.249^{* *}$ & 1 & & & \\
\hline 10. Sleep Disturbances & 0.062 & 0.063 & 0.037 & 0.062 & $0.348^{* *}$ & 0.032 & $0.415^{* *}$ & $0.206^{* *}$ & $0.224^{* * *}$ & 1 & & \\
\hline 11. Daytime Dysfunction & $-0.202^{* *}$ & -0.072 & -0.062 & $-0.140^{*}$ & $0.169^{*}$ & $0.451^{* *}$ & $0.197^{* *}$ & $0.264^{* *}$ & $0.144^{*}$ & $0.199^{* *}$ & 1 & \\
\hline 12. C-PSQI & $-0.141^{*}$ & -0.094 & -0.101 & -0.131 & $0.599^{* *}$ & $0.386^{* *}$ & $0.640^{* *}$ & $0.668^{* *}$ & $0.548^{* *}$ & $0.595^{* *}$ & $0.555^{* *}$ & 1 \\
\hline
\end{tabular}

Table 5. Stepwise multiple regression analysis for learning satisfaction and its related factors.

\begin{tabular}{cccccc}
\hline Variable & $\mathrm{B}$ & $\beta$ & $\mathrm{t}$ & $\mathrm{R}^{2}$ & $\mathrm{~F}$ \\
\hline Constant & 3.43 & & 40.01 & & \\
Interest in nursing & -0.14 & -0.32 & -4.85 & 0.102 & $23.59^{* * *}$ \\
\hline
\end{tabular}

${ }^{* *} \mathrm{p}<0.01$.

fied" and "satisfied". This finding is consistent with that of the Wang and Lin [1] study, which investigated perceptions toward the caring behavior of clinical nursing instructors and learning satisfaction among 296 nursing students of a junior college of healthcare management, and found that overall learning satisfaction among the nursing students was between "highly satisfied” and "satisfied”. In this study, students had the highest learning satisfaction in the cognitive domain and the lowest satisfaction in the affective domain. Such may reflect the general nursing students had sufficient professional knowledge, at present, the. Nevertheless, this finding was contradictory with a study by Lofmark and Wikblad [23], which reported that the general nursing students had insufficient theoretical knowledge. Leigler [24] indicated that the goal of nursing education is to establish the knowledge and skills of students for providing clinical care.

This study found the lowest satisfaction toward the affective domain, which is consistent with the finding of the Feng et al. [25] study, which examined the learning effectiveness of 264 students adopting different admission channels. That study showed that students of the Department of Healthcare Management had fair performance, with a mean score in the affective domain of learning effectiveness of 3.21 points. The literature had suggested that the nurturing of moral character and the establishment of values lie in affective domain learning, which also affects students’ professional spirit and attitudes in the future work [3] [4]. The nursing specialty serves humans, and thus human-centered consideration is a core value of nursing. The cultivation of humanistic literacy helps nurses hold a human-centered philosophy when confronted with the impact of changes in the healthcare structure and values [21] [26]. However, given current management practices, which value technology and cost-efficiency, nurses face several challenges. As a result, in addition to instructing professional knowledge and skills, nursing instructors could also emphasize students' learning in the affective domain, which includes the nurturing of moral character and the establishment of values to strengthen students' humanistic literacy.

Additionally, Cronbach's alpha, based on a set of items' mean interitem correlation, is the most popular statistic testing internal consistency [21], the Cronbach's $\alpha$ value of Learning Satisfaction Scale for this study was 
0.96, higher than the original scale [1]. Dennick and Tavakol [27] indicated that reliability is the consistency to measure the degree of error, respondents, situational factors can be caused by the error. Participants in the original scale [1], including the different school systems and fill out the questionnaire on end of their internships, however, this study was not. Perhaps resulting in Cronbach's $\alpha$ of the two study differences. A high value of alpha ( $>0.90)$ may suggest redundancies [21]. Therefore, future research should pay attention to the appropriateness of the research tools and the test length should be shortened.

\subsection{Relationship among Demography, Sleep Quality and Learning Satisfaction}

A significant relationship was found between affective domain of learning satisfaction and C-PSQI score, means that students with better sleep quality had a higher score in the affective domain of learning satisfaction, a finding similar to Feng et al. [25]. Such may reflect that nursing education is highly professional, and nursing practices serve human individuals, abilities such as interpersonal interaction and communication and crisis management are essential to nurses. As a result, teaching in the affective domain, which emphasizes the nurturing of moral character and values, is necessary in nursing education. The authors therefore recommend that nursing students receive sleep health education to enhance learning effectiveness in the affective domain, which establishes students' attitudes and values.

The results of this study showed that lower scores of subjective sleep quality, use of sleep medication, or daytime dysfunction brought higher overall learning satisfaction, a finding consistent with prior studies [15] [28] that demonstrated that subjective sleep quality is a key predicting factor of sleep quality, and long-term sleep disorder not only affects physical and mental conditions, but indirectly influences learning efficiency.

There was a significant difference between interest in nursing (demographic characteristics) and learning satisfaction in this study. Students who were more interested in nursing had greater learning satisfaction in the affective and psychomotor domains. This finding was consistent with Wang and Lin [1] found that students possessing higher interest in nursing practices had higher learning satisfaction.

The major predictor of learning satisfaction was "interest in nursing", accounting for $10.2 \%$ of learning satisfaction variance in this study. This finding indicates that individual with more concerned about their personal interests, sense of achievement, self-development, social interaction, and health and leisure activities, and therefore value their jobs in terms of its achievement, development, and material rewards [29]. Therefore, under these circumstances, cultivating the interest of nursing students toward nursing practices not only enhances their learning satisfaction, but benefits their career planning.

\section{Conclusions}

The present study found that $53 \%$ of students had poor sleep quality, and that the level of overall learning satisfaction among students was between "highly satisfied" and "satisfied". In addition, the lowest learning satisfaction toward the affective domain. Results showed "interest in nursing" to be significantly associated with learning satisfaction. The application of several interventions might facilitate the learning satisfaction: 1) course design emphasize affective domain of teaching objectives, strengthen students' self-perceptions, humanistic education, the nurturing of moral character; 2) applications of affective teaching strategies such as problem solving, experiential learning, and concerns for humans could be addressed; 3) assist nursing students in planning their nursing career, cultivating the interest of nursing students toward nursing practices is a priority.

Based on the results of this study, a larger sample size is recommended to strengthen the significance of the finding. As the study targeted a nursing college, it may be subject to regional limitation. Also, subjects recruited form different college population are recruited. Additionally, this study was a cross-sectional design and used questionnaires, which may have been subjective to bias from respondents when answering question, could not identify changes in learning satisfaction over time. Moreover, utilizing an objective instrument such as students' score and polysomnography are recommended for further study. A longitudinal study with physiologic analysis is recommended for further study to find the correlation between learning satisfaction and sleep quality.

\section{Acknowledgements}

The authors would like to thank the participants who completed the questionnaire. We also sincerely thank the Ministry of Science and Technology, for financially supporting this research (NSC 99-2815-C-255-004-S). 


\section{References}

[1] Wang, C.S. and Lin S.H. (2006) Perceived Concern of Nursing School Instructor: Effects on Learning Ability of Junior College Nursing Students. The Journal of Health Science, 8, 213-228.

[2] Bloom, B.S. (1956) Taxonomy of Educational Objectives: The Classification of Educational Goals. Handbook I, Cognitive Domain, 1 Edition, Longmans, New York.

[3] Wang, R.Z. (2010) Analysis Student Learning. Evaluation Bimonthly, 27, 62.

[4] Cate, T.J.T. and Haes, J.C.J. (2000) Summative Assessment of Medical Students in the Affective Domain. Medical Teacher, 22, 40-43. http://dx.doi.org/10.1080/01421590078805

[5] Chao, Y.F.C. (2000) Nursing Education to Share Experiences. Journal of Medical Education, 4, 410-412.

[6] Hanson, K.J. and Stenvig, T.E. (2008) The Good Clinical Nursing Educator and the Baccalaureate Nursing Clinical Experience: Attributes and Praxis. Journal of Nursing Education, 47, 38-42. http://dx.doi.org/10.3928/01484834-20080101-04

[7] Brown, F.C., Soper, B.J. and Buboltz, W.C. (2001) Prevalence of Delayed Sleep Phase Syndrome in University Students. College Student Journal, 35, 472-477.

[8] Vail-Smith, K., Felts, W. and Becker, C. (2009) Relationship between Sleep Quality and Health Risk Behaviors in Undergraduate College Students. College Student Journal, 43, 924-930.

[9] Tsai, L.L. and Li, S.P. (2004) Sleep Patterns in College Students Gender and Grade Difference. Journal of Psychosomatic Research, 56, 231-237. http://dx.doi.org/10.1016/S0022-3999(03)00507-5

[10] Glozier, N., Martiniuk, A., Patton, G., Ivers, R., Li, Q. and Hickie, L. (2010) Short Sleep Duration in Prevalent and Persistent Psychological Distress in Young Adults: The Drive Study. Sleep, 33, 1139-1145.

[11] Christopher, G.V., George, S.B., Devan, J. and Robbert, H. (2009) Sleep Deprivation Impairs cAMP Signaling in the Hippocampus. Nature, 461, 1122-1125. http://dx.doi.org/10.1038/nature08488

[12] Forquer, L.M., Camden, A.E., Gabriau, K.M. and Johnson, C.M. (2008) Sleep Patterns of College Students at a Public University. Journal of American College Health, 56, 563-565. http://dx.doi.org/10.3200/JACH.56.5.563-565

[13] Liu, X. (2004) Sleep and Adolescent Suicidal Behavior. Sleep, 27, 1351-1358.

[14] Meijer, A.M., Habekothe, H.T. and Van Den Wittenboer, G.L. (2000) Time in Bed, Quality of Sleep and School Functioning of Children. Journal of Sleep Research, 9, 145-153. http://dx.doi.org/10.1046/j.1365-2869.2000.00198.x

[15] Meijer, A.M. and Wittenboer, G.L.H. (2004) The Joint Contribution of Sleep, Intelligence and Motivation to School Performance. Personality and Individual Differences, 37, 95-106. http://dx.doi.org/10.1016/j.paid.2003.08.002

[16] Wolfson, A.R. and Carskadon, M.A. (2003) Understanding Adolescents' Sleep Patterns and School Performance; a Critical Appraisal. Sleep Medicine Reviews, 7, 491-506. http://dx.doi.org/10.1016/S1087-0792(03)90003-7

[17] Curcio, G., Ferrara, M. and Gennaro, L.D. (2006) Sleep Loss, Learning Capacity and Academic Performance. Sleep Medicine Reviews, 10, 323-337. http://dx.doi.org/10.1016/j.smrv.2005.11.001

[18] Chung, K.F. and Cheung, M.M. (2008) Sleep-Wake Patterns and Sleep Disturbance among Hong Kong Chinese Adolescents. Sleep, 31, 185-194.

[19] Lazaratou, H., Dikeos, D.G., Anagnostopoulos, D.C., Sbokou, O. and Soldatos, C.R. (2005) Sleep Problem in Adolescence a Study of Senior High School Students in Greece. Euro Child Adolescent Psychiatry, 14, 237-243. http://dx.doi.org/10.1007/s00787-005-0460-0

[20] Polit, D.F. and Beck, C.T. (2008) Nursing Research: Generating and Assessing Evidence for Nursing Practice. Lippincott Williams and Wilkins, Philadelphia.

[21] Chiang, C.H. (2007) Effects of Sleep Education on Sleep Knowledge, Sleep Pattern, and Emotion in University Students. Master's Thesis, Airiti Library.

[22] Buysse, D.J., Reynolds III, C.F., Monk, T.H., Berman, S.R. and Kupfer, D.J. (1989) The Pittsburgh Sleep Quality Index: A New Instrument for Psychiatric Practice and Research. Psychiatry Research, 28, 193-213. http://dx.doi.org/10.1016/0165-1781(89)90047-4

[23] Lofmark, A. and Wikblad, K. (2001) Facilitating and Obstructing Factors for Development of Learning in Clinical Practice: A Student Perspective. Journal of Advanced Nursing, 34, 43-50. http://dx.doi.org/10.1046/j.1365-2648.2001.3411739.x

[24] Leigler, R.M. (1997) Predicting Students' Satisfaction in Baccalaureate Nursing Programs: Testing a Causal Model. Journal of Nursing Education, 35, 66-73.

[25] Feng, C.K., Pan, L.C. and Chen, M.L. (2007) Analysis of Students' Learning Performance among Different College Entrance Paths-A Study of Students in Health Administration at a Technological University. Journal of Healthcare 
Management, 8, 85-103.

[26] Chou, C.C., Wu, L.J. and Lin, Y.C. (2007) Humanity Education in Nursing. The Journal of Nursing, 54, $29-34$.

[27] Dennick, R. and Tavakol, M. (2011) Making Sense of Cronbach’s Alpha. International Journal of Medical Education, 2, 53-55. http://dx.doi.org/10.5116/ijme.4dfb.8dfd

[28] Millman, R.P. (2005) Excessive Sleepiness in Adolescents and Young Adults: Causes, Consequences, and Treatment Strategies. Pediatrics, 115, 1774-1786. http://dx.doi.org/10.1542/peds.2005-0772

[29] Huang, L.L. and Lin, L.F. (2007) Difference of the Works Values in Disparity Generation Nursing Staffs: Systematic Literature Review. Cheng Vhing Medical Journal, 3, 44-50. 
Scientific Research Publishing (SCIRP) is one of the largest Open Access journal publishers. It is currently publishing more than 200 open access, online, peer-reviewed journals covering a wide range of academic disciplines. SCIRP serves the worldwide academic communities and contributes to the progress and application of science with its publication.

Other selected journals from SCIRP are listed as below. Submit your manuscript to us via either submit@scirp.org or Online Submission Portal.
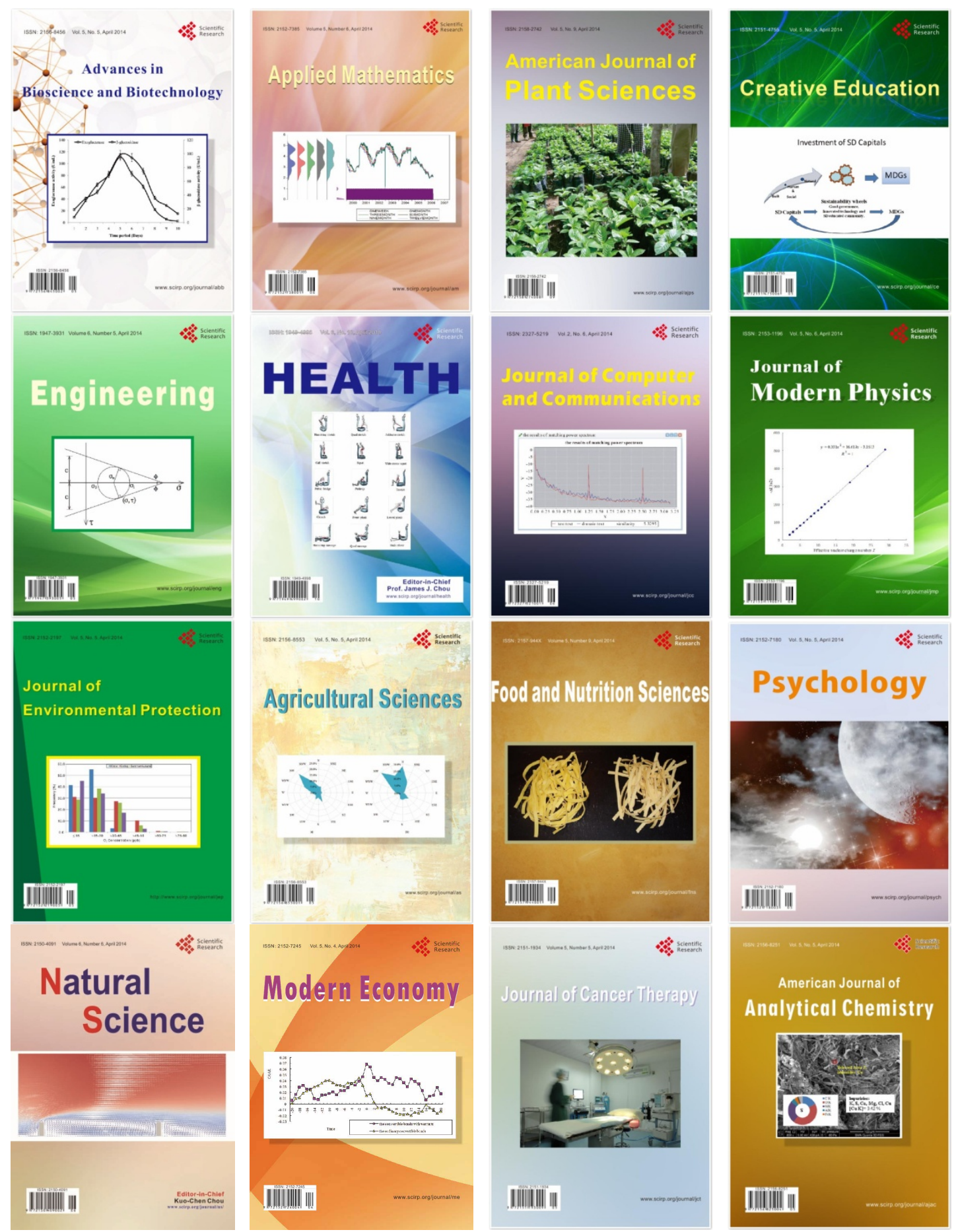